\title{
ARTICLE
}

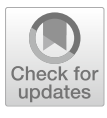

Cite as

Nano-Micro Lett.

(2021) 13:79

Received: 17 November 2020 Accepted: 28 December 2020 Published online: 23 February 2021 (c) The Author(s) 2021

\section{Regulating Zn Deposition via an Artificial Solid-Electrolyte Interface with Aligned Dipoles for Long Life Zn Anode}

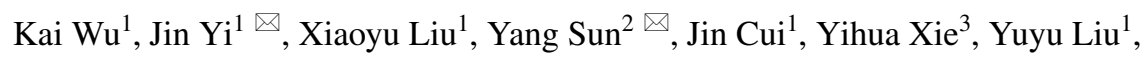 \\ Yongyao $\mathrm{Xia}^{3}$, Jiujun Zhang ${ }^{1}$
}

\section{HIGHLIGHTS}

- An artificial solid-electrolyte interface composed of a perovskite type material, $\mathrm{BaTiO}_{3}$, is introduced to $\mathrm{Zn}$ anode surface in aqueous zinc ion batteries.

- The $\mathrm{BaTiO}_{3}$ layer endowing inherent character of the switched polarization can regulate the interfacial electric field at anode/electrolyte interface.

- $\mathrm{Zn}$ dendrite can be restrained, and $\mathrm{Zn}$ metal batteries based on $\mathrm{BaTiO}_{3}$ layer show stable cycling.

ABSTRACT Aqueous zinc ion batteries show prospects for next-generation renewable energy storage devices. However, the practical applications have been limited by the issues derived from $\mathrm{Zn}$ anode. As one of serious problems, $\mathrm{Zn}$ dendrite growth caused from the uncontrollable $\mathrm{Zn}$ deposition is unfavorable. Herein, with the aim to regulate $\mathrm{Zn}$ deposition, an artificial solid-electrolyte interface is subtly engineered with a perovskite type material, $\mathrm{BaTiO}_{3}$, which can be polarized, and its polarization could be switched under the external electric field. Resulting from the aligned dipole in $\mathrm{BaTiO}_{3}$ layer, zinc ions could move in order during cycling process. Regulated Zn migration at the anode/ electrolyte interface contributes to the even $\mathrm{Zn}$ stripping/ plating and confined $\mathrm{Zn}$ dendrite growth. As a result, the

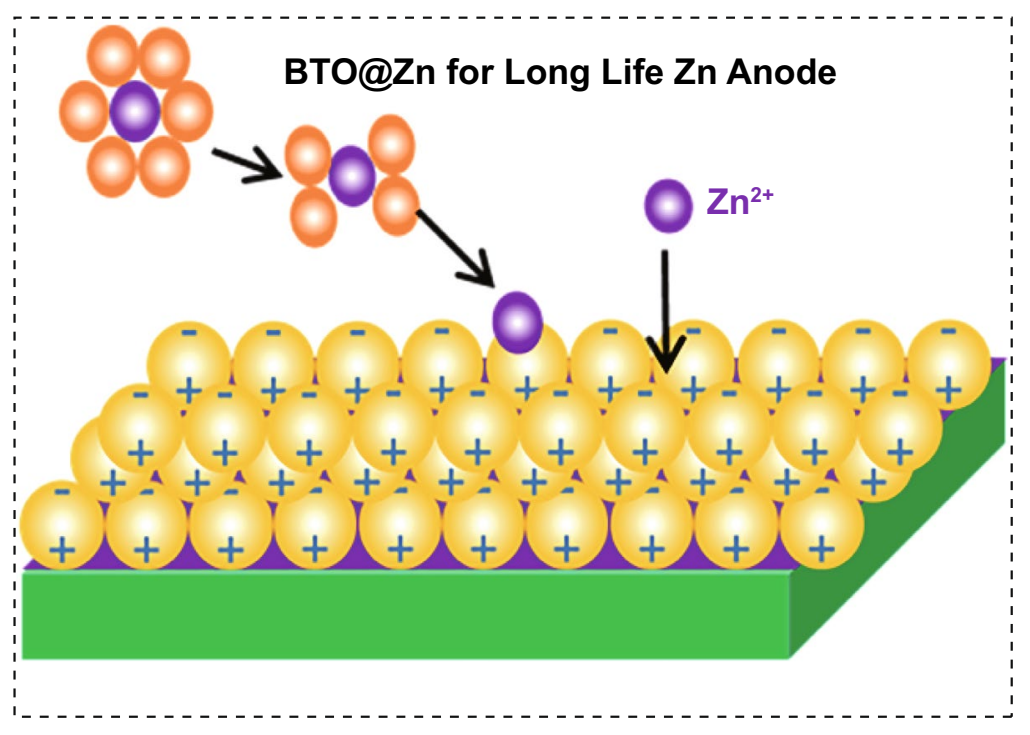
reversible $\mathrm{Zn}$ plating/stripping processes for over $2000 \mathrm{~h}$ have been achieved at $1 \mathrm{~mA} \mathrm{~cm}{ }^{-2}$ with capacity of $1 \mathrm{mAh} \mathrm{cm}^{-2}$. Furthermore, this anode endowing the electric dipoles shows enhanced cycling stability for aqueous $\mathrm{Zn}-\mathrm{MnO}_{2}$ batteries. The battery can deliver nearly $100 \%$ Coulombic efficiency at $2 \mathrm{~A} \mathrm{~g}^{-1}$ after 300 cycles.

KEYWORDS Regulated Zn deposition; Artificial solid-electrolyte interface; Perovskite type dielectric material; Zn anode; $\mathrm{Zn}$ ion battery

\footnotetext{
Jin Yi,jin.yi@shu.edu.cn; Yang Sun, sunyang5@mail.sysu.edu.cn; Jiujun Zhang, jiujun.zhang@i.shu.edu.cn

1 Institute for Sustainable Energy/College of Sciences, Shanghai University, 99 Shangda Road, Shanghai 200444, People's Republic of China

2 School of Materials, Sun Yat-Sen University, Guangzhou 510006, People's Republic of China

3 Department of Chemistry and Institute of New Energy, Fudan University, Shanghai 200433, People's Republic of China
} 


\section{Introduction}

Aqueous zinc ion battery (ZIB) is considered to be a competitive alternative for next-generation renewable energy storage devices by virtue of high theoretical volume capacity of metal $\mathrm{Zn}$ anode $\left(5854 \mathrm{mAh} \mathrm{cm}^{-3}\right)$, nontoxicity and high safety [1-4]. By now, several rechargeable ZIBs employing mild acid aqueous electrolyte, such as $\mathrm{Zn}-\mathrm{MnO}_{2}$ [5-7], $\mathrm{Zn}$ $\mathrm{V}_{2} \mathrm{O}_{5}$ [8-11], Zn-hexacyanoferrate $[12,13]$ and so on, have delivered favorable electrochemical performance. However, the challenge related to $\mathrm{Zn}$ dendrite growth is still an urgent issue, which impacts the future practical application.

Unfortunately, compared to nonaqueous lithium-ion batteries, there is lack of a solid-electrolyte interface (SEI) in aqueous ZIBs, which could effectively protect $\mathrm{Zn}$ anode [14-17]. Accordingly, an artificial SEI introduced to the surface of $\mathrm{Zn}$ anode would be a promising strategy to suppress zinc dendrites. $\mathrm{CaCO}_{3}$ [18], polyamide [19], $\mathrm{TiO}_{2}$ [20, 21], metal-organic framework [22, 23], $\mathrm{ZnO}$ [24], hydrogen-substituted graphdiyne [25], etc., serving as artificial SEI layers, have successfully facilitated uniform $\mathrm{Zn}$ plating/stripping. Furthermore, it would show positive prospects that an artificial SEI controlling electric field at the interface would promote even $\mathrm{Zn}$ plating/stripping. Guided by the controlled interfacial electric field, homogenous charge would distribute at the interface, availing the redox kinetic processes in battery, where reversible process of even Zn plating/stripping could be effortless [26]. Subsequently, Zn dendrite would be confined. Whereupon, how to achieve the ability to control the interfacial electric field for the artificial SEI is significant. As is well known, dielectric materials can be polarized under an external electric filed [27]. In addition, the polarization can be parallel to the applied electric field. $\mathrm{BaTiO}_{3}$ (BTO), a typical perovskite type material with $\mathrm{ABO}_{3}$ structure, has been currently employed for energy storage composite [28]. Under the applied electric field, the polarization of an ionically bonded crystal dielectric material is produced, which results from the movement of cation from the center of the symmetry site [29]. In BTO structure, $\mathrm{Ti}^{4+}$ cation is in the $\left[\mathrm{TiO}_{6}\right]$ octahedral interstitial sites [30]. Thus, under an external electric field, $\mathrm{Ti}^{4+}$ could be deviated from the center of the $\left[\mathrm{TiO}_{6}\right]$. Subsequently, electric dipoles induce polarized electric field on the surface. Moreover, the polarization can be switched by the external electric field [31-33]. As a proof-of-concept, BTO is captured to construct the artificial SEI, producing directional electric field to regulate $\mathrm{Zn}$ solvation/deposition. Figure 1 illustrates the proposed process of zinc ion migration on bare Zn and BTO-coated Zn foil (BTO@Zn) during Zn plating/ stripping. Zinc ion can be stripped in order from BTO@Zn, while the unordered zinc ion movement takes place on the bare zinc foil surface during stripping process in Fig. 1a, b. It is speculated that both the uniform ion pathways and directional dipoles supplied by the BTO layer can guide ordered migration of zinc ions. The ion pathways physically restrain the disorderly movement of $\mathrm{Zn}^{2+}$, and dipoles construct even electric field at SEI to make zinc ions liberate in order. Additionally, zinc ions can be regulated to electroplate uniformly, resulting from the directional dipoles switched by the applied electric field. A dense deposited Zn layer without dendrites is formed between BTO layer and Zn anode (Fig. 1b). On the contrary, Zn prefers to nucleate locally, then accumulates at the initial deposited area on bare $\mathrm{Zn}$ foil during plating process. Hence, irregular zinc dendrites are formed. Compared to bare $\mathrm{Zn}$ foil, $\mathrm{Zn}$ dendrite growth would be restrained effectively by BTO layer. Favorable electrochemical performance has been obtained in the symmetric cells and aqueous ZIBs based on BTO@Zn foil. The uniform Zn plating in the symmetric cells with BTO@Zn has been achieved at the current density of $1 \mathrm{~mA} \mathrm{~cm}{ }^{-2}$ with areal capacity of $1 \mathrm{mAh} \mathrm{cm}^{-2}$ over 1000 cycles. When the current density and areal capacity are raised up to $5 \mathrm{~mA} \mathrm{~cm}^{-2}$ and $2.5 \mathrm{mAh}$ $\mathrm{cm}^{-2}$, respectively, the symmetric cell with BTO@Zn can operate over 1500 cycles. Impressively, compared to the ones with bare $\mathrm{Zn}$, aqueous $\mathrm{Zn}-\mathrm{MnO}_{2}$ batteries employing BTO@Zn anode reveal enhanced electrochemical performances and deliver nearly $100 \%$ Coulombic efficiency at $2 \mathrm{~A} \mathrm{~g}^{-1}$ after 300 cycles.

\section{Experimental}

\subsection{Materials}

$\mathrm{BaTiO}_{3}(\mathrm{BTO},<100 \mathrm{~nm})$ and $\mathrm{ZnSO}_{4} \cdot 7 \mathrm{H}_{2} \mathrm{O}$ were purchased from Aladdin, China. $\mathrm{KMnO}_{4}$ was purchased from Energy Chemistry, China. Ti foil was $0.03 \mathrm{~mm}$. 
(a)
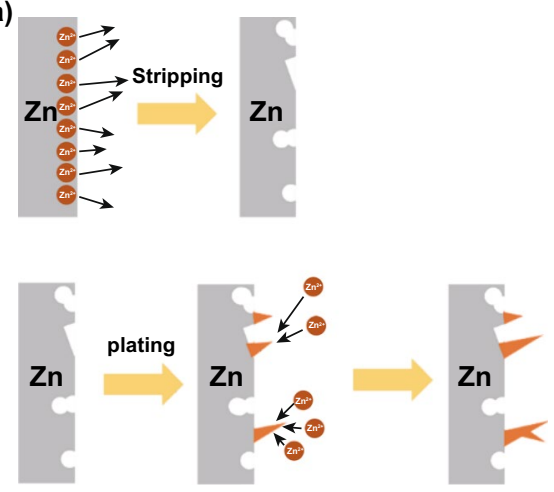

(c)

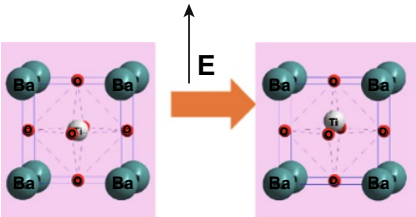

(e)

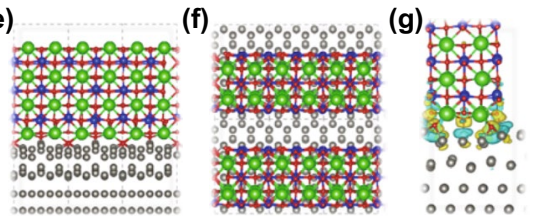

(b)
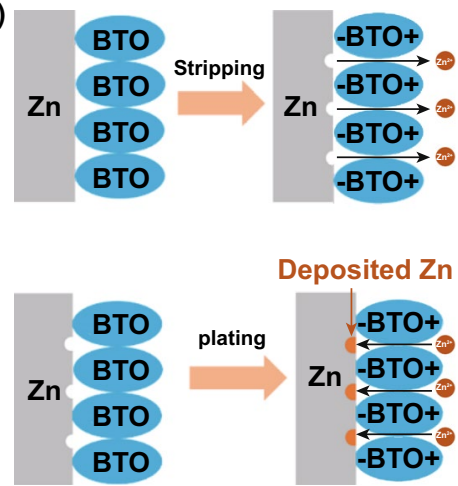

(d)
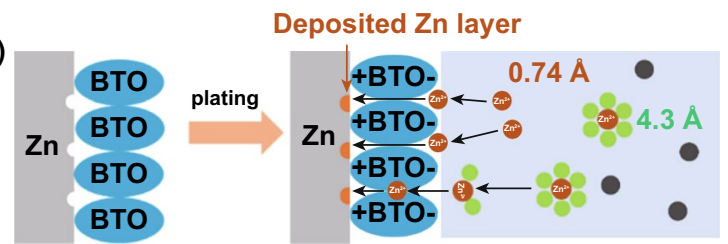

(h)
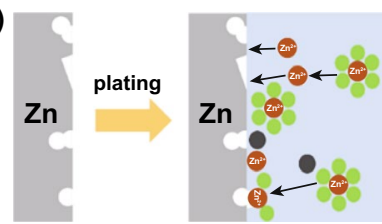

(שro: - BTO dipoles

- $\mathrm{Zn}$ ion $\bullet \mathrm{SO}_{4}^{2-}$

- $\mathrm{H}_{2} \mathrm{O}$

Fig. 1 Schematic of zinc ion transport during Zn stripping/plating for: a bare Zn, b BTO@Zn foil. c Schematic diagram of the Ti ion migration in the $\left[\mathrm{TiO}_{6}\right]$ octahedral interstitial sites under the external electric field. d Schematic of the mechanism of zinc ion transport at the BTO@Zn/ electrolyte interface during Zn plating process. Schematic illustration of the BTO@Zn surface used in the simulation: e side view, $\mathbf{f}$ top view. The bottom two $\mathrm{Zn}$ layers are fixed during the geometrical optimization. $\mathrm{Ba}, \mathrm{Ti}, \mathrm{O}, \mathrm{Zn}$ atoms are represented by green, blue, red, gray spheres, respectively. g Differential charge density $\left(\rho_{\text {diff }}=\rho_{\mathrm{BTO}} @ \mathrm{Zn}-\rho_{\mathrm{BTO}}-\rho_{\mathrm{Zn}}\right)$ of the BTO@Zn surface. Yellow and blue surfaces indicate the electron gain and loss, respectively. $\mathbf{h}$ Schematic diagram of zinc ion transport at the $\mathrm{Zn}$ anode/electrolyte interface during $\mathrm{Zn}$ plating process

\subsection{Preparation of BTO@Zn Foil}

A slurry was composed of BTO and poly(vinylidene fluoride) (PVDF) in a weight ratio of 9:1 in $N$-methyl pyrrolidone (NMP) solvent, then which was coated on $\mathrm{Zn}$ foil. The foil was dried in vacuum at $80{ }^{\circ} \mathrm{C}$ overnight. The areal loading of BTO was about $1 \mathrm{mg} \mathrm{cm}^{-2}$.

\subsection{Preparation of $\mathrm{MnO}_{2}$ Electrode}

$\mathrm{KMnO}_{4}(2 \mathrm{~g})$ powders were calcined at $500{ }^{\circ} \mathrm{C}$ for $5 \mathrm{~h}$ at the condition of $5{ }^{\circ} \mathrm{C} \mathrm{min}^{-1}$, then naturally cooled down to room temperature. Afterward, the obtained powders were washed by centrifugation with distilled water and ethanol until the purple of solution was eliminated. The products were dried at $80{ }^{\circ} \mathrm{C}$ for $12 \mathrm{~h}$. The cathode was mixed by $70 \mathrm{wt} \%$ of as-prepared $\mathrm{MnO}_{2}, 20 \mathrm{wt} \%$ Super P and $10 \mathrm{wt} \%$ poly(tetrafluoroethylene) (PTFE) to form thin film. After drying, the thin film was pressed at Ti mesh. The areal loading of $\mathrm{MnO}_{2}$ was about $2 \mathrm{mg} \mathrm{cm}^{-2}$.

\subsection{Material Characterization}

The morphologies were detected by using a scanning electron microscope (SEM, HITACHI S-4800). XRD patterns of the samples were obtained using powder XRD analysis (Bruker D8 Advance, Germany) with $\mathrm{Cu} \mathrm{K} \alpha$ radiation $(\lambda=0.15406 \mathrm{~nm})$, operating at $40 \mathrm{kV} \times 40 \mathrm{~mA}$.

\subsection{Electrochemical Tests}

All of the cells and batteries were assembled as coin cells (CR2016) in ambient environment. In the symmetric cells, 
Zn (thickness $\sim 0.03 \mathrm{~mm}$, a disk of $12 \mathrm{~mm}$ in diameter) or BTO@Zn and glass fiber served as electrode and separator, respectively. The $\mathrm{Zn}-\mathrm{Ti}$ cells employed Ti foil as the working electrode and zinc or BTO@Zn foil worked as counter and reference electrodes. To investigate the nucleation behavior, the cutoff voltage was set as $1 \mathrm{~V}$ at the current density of $5 \mathrm{~mA} \mathrm{~cm}^{-2}$ with the areal capacity of $5 \mathrm{mAh} \mathrm{cm}^{-2}$. Tafel plot measurement was carried out at $5 \mathrm{mV} \mathrm{s}^{-1}$ with Zn or BTO@ $\mathrm{Zn}$ as the working electrode, $\mathrm{Pt}$ foil as the counter electrode and $\mathrm{Ag} / \mathrm{AgCl}$ as the reference electrode. The electrolyte for the symmetric cells was $2 \mathrm{M} \mathrm{ZnSO}_{4}$ aqueous solution prepared by $\mathrm{ZnSO}_{4} \cdot 7 \mathrm{H}_{2} \mathrm{O}$ and distilled water. To verify the feasibility of BTO@Zn, Zn- $\mathrm{MnO}_{2}$ batteries based on bare $\mathrm{Zn}$ andBTO@Zn were fabricated, respectively.Zn or BTO@Zn was used as the anode, $\mathrm{MnO}_{2}$ was the cathode and glass fiber was the separator. The electrolyte for $\mathrm{Zn}-\mathrm{MnO}_{2}$ batteries was $2 \mathrm{M} \mathrm{ZnSO}_{4}$ and $0.1 \mathrm{M} \mathrm{MnSO}_{4}$ aqueous solution. The cyclic voltammogram $(\mathrm{CV})$ profiles were carried out on an electrochemical workstation CHI760E (ChenHua, Shanghai, China) at a scan rate of $1 \mathrm{mV} \mathrm{s}^{-1}$ under potential control (1-1.8 V). $\mathrm{MnO}_{2}$ served as a working electrode and zinc foil worked as counter and reference electrodes. Electrochemical impedance spectroscopy (EIS) was conducted on a Solartron analytical electrochemical workstation (1470E) in the frequency range of $10^{-2}-10^{6} \mathrm{~Hz}$. Galvanostatic charge/discharge cycling measurements were conducted on a LANHE CT2001A (Wuhan, China) battery testing instrument.

\subsection{Calculations}

Density functional theory calculations (DFT) were conducted utilizing the Vienna Ab initio Simulation Package (VASP) within the projector augmented-wave approach [34-36]. Generalized gradient approximation (GGA) in the parameterization of Perdew, Burke, and Ernzerhof (PBE) pseudopotential was utilized to confirm the exchange-correlation potential [37]. The dimension of the supercell is $8.0 \times 13.8 \times 27.4 \AA^{3}$, containing $72 \mathrm{Zn}$ atoms, $16 \mathrm{Ba}$ atoms, $18 \mathrm{Ti}$ atoms and $54 \mathrm{O}$ atoms. The plane-wave cutoff was controlled to $520 \mathrm{eV}$. Geometry optimizations were carried out by taking advantage of a conjugate gradient minimization until all of the forces acting on ions were less than $0.01 \mathrm{eV} / \AA$ per atom. The $\Gamma$ point was used in for the Brillouin zone sampling. The formation energy of depositing a Zn atom on the bare Zn or BTO@Zn surface is evaluated by the following equations:
$E_{\text {bare Zn }}^{f}=E_{\mathrm{Zn} \_ \text {atom@bare_Zn }}-E_{\mathrm{Zn} \_ \text {atom }}-E_{\text {bare_Zn }}$

$E_{\mathrm{BTO} @ \mathrm{Zn} .}^{f}=E_{\mathrm{Zn} \_ \text {atom@BTO@Zn }}-E_{\mathrm{Zn} \_ \text {atom }}-E_{\mathrm{BTO} @ \mathrm{Zn}}$

where the $E_{\mathrm{Zn} \_ \text {atom }}$ is the energy of a single $\mathrm{Zn}$ atom; $E_{\text {bare_Zn }}$ and $E_{\mathrm{BTO} @ \mathrm{Zn}}$ are the energy of bare Zn surface and BTO@ $\mathrm{Zn}$ surface, respectively; $E_{\mathrm{Zn} \_ \text {atom } @ \text { bare_Zn }}$ is the total energy of bare $\mathrm{Zn}$ surface with an extra $\mathrm{Zn}$ atom; $E_{\mathrm{Zn} \_ \text {atom@BTo@Zn }}$ is the total energy of BTO@Zn surface with an extra Zn atom.

\section{Results and Discussion}

\subsection{Mechanism of $\mathrm{Zn}^{2+}$ Transport at Anode/Electrolyte Interface}

To further understand the evolution of $\mathrm{Zn}$ stripping/plating, a detailed depiction is also shown in Fig. 1. Under an external electric field, the Ti ion can be deviated from the center of the symmetrical site, $\left[\mathrm{TiO}_{6}\right]$ (Fig. 1c). It is considered that BTO can be polarized by the external field during charging/discharging processes [38]. Thereby, a directional electric field on BTO layer surface is provided when discharging. Moreover, the BTO layer renders considerably uniform ion pathways. Hence, zinc ions can be stripped from anode in order, subsequently enter into the electrolyte. These zinc ions coordinate with solvents generating the hydrated $\mathrm{Zn}$ ions $\left(\mathrm{Zn}\left(\mathrm{H}_{2} \mathrm{O}\right)_{6}{ }^{2+}\right)$ until the stripping process terminates. Subsequently, during plating process, $\mathrm{Zn}\left(\mathrm{H}_{2} \mathrm{O}\right)_{6}{ }^{2+}$ ions are required to undergo desolvation process during which $\mathrm{Zn}\left(\mathrm{H}_{2} \mathrm{O}\right)_{6}{ }^{2+}$ ions $(4.3 \AA)$ transform into $\mathrm{Zn}^{2+}$ ions (0.74 $\AA$ ) [39]. In the following, zinc ions are plated on the $\mathrm{Zn}$ anode surface. However, for the bare $\mathrm{Zn}$, only a few nuclei sites induce zinc ion to nucleate, which would cause the uneven $\mathrm{Zn}$ plating [40]. In addition, during the desolvation process of $\mathrm{Zn}\left(\mathrm{H}_{2} \mathrm{O}\right)_{6}{ }^{2+}$ ion, the species of decomposition, passivation and byproduct would be produced and adhere to the $\mathrm{Zn}$ anode surface [41]. Fortunately, in Fig. 1d, the direction of BTO polarization is switched by the employed electric field during plating process. Negative charges will concentrate on the element $\mathrm{O}$ of $\mathrm{Ti}-\mathrm{O}$ due to the surface ordered electric field of BTO. A certain amount of $\mathrm{SO}_{4}{ }^{2-}$ anions could be rejected by the $\mathrm{BTO}$ layer due to the electrostatic repulsion. The interaction between cations and anions gets weak; then, the side reactions would be suppressed [42]. Additionally, the water molecules of hydrated zinc ion can 
be attracted by the element $\mathrm{O}$ of $\mathrm{Ti}-\mathrm{O}$, which enriches negative charges. It is possible that hydrogen bond can be constructed between the $\mathrm{H}$ atom of $\mathrm{H}_{2} \mathrm{O}$ and the $\mathrm{O}$ atom of Ti-O. A solid-liquid interface could be formed to promote the fast ion transfer [43]. Herein, benefiting from the ordered electric field, the free de-hydrated zinc ions could be accelerated to pass through BTO layer. More nucleation sites can be provided for even Zn plating. Furthermore, density functional theory (DFT) calculations were performed to demonstrate the merit of the $\mathrm{BaTiO}_{3}$ absorbate in electrochemically depositing $\mathrm{Zn}$ metal. In Fig. 1e, f, a BTO nano-rod is put on top of the $\mathrm{Zn}$ layer to simulate the BTO@Zn surface. A charge transfer from the Zn atoms to the $\mathrm{O}$ atoms of BTO was identified (Fig. 1g). Compared with the bare $\mathrm{Zn}$ surface, the formation energy of depositing an extra $\mathrm{Zn}$ atom on the BTO@ $\mathrm{Zn}$ surface is much lower ( -2.28 vs. $-0.35 \mathrm{eV}$ ), suggesting that the electrochemical Zn plating would preferentially take place in the vicinity of the BTO area. Therefore, it could be reasonably concluded that the electrochemical $\mathrm{Zn}$ deposition could be regulated by the presence of BTO adsorbates. In addition, the ion pathways furnished by BTO layer physically restrict two-dimension diffusion of zinc ions at the interface on account of the BTO electrochemical inertia [44]. Fortunately, the BTO SEI facilitates the dense Zn plating without dendrites. On the contrary, certain hydrated $\mathrm{Zn}^{2+}$ ions and sulfate would be attracted in the vicinity of bare $\mathrm{Zn}$ anode. After performing the desolvation process, zinc ions migration would be obstructed by these ions; subsequently, $\mathrm{Zn}$ would be gradually plated at the local area (Fig. 1h). The $\mathrm{Zn}$ dendrites are inevitably produced.

\subsection{Electrochemical Properties of the Symmetric Cells}

Compared to the XRD patterns of commercial BTO and $\mathrm{Zn}$ foil, it can be found that BTO is successfully coated on $\mathrm{Zn}$ foil, as demonstrated by the typical diffraction peaks are observed at $22.1^{\circ}$ and $31.5^{\circ}$ (Fig. S1). The size of BTO is less than $100 \mathrm{~nm}$, determined by scanning electron microscopy (SEM) image (Fig. S2). An artificial SEI has been constructed on $\mathrm{Zn}$ foil through coating BTO layer $(\sim 1 \mu \mathrm{m})$ (Fig. S3). Generally, Zn suffers from corrosion in the electrolyte. Under the protection of BTO layer, the Zn anode corrodes less, which is further demonstrated by Tafel plot in Fig. S4. The corrosion potential of BTO@Zn shows no obvious change in comparison with the one of bare $\mathrm{Zn}$, while it can be found that lower corrosion current is achieved for BTO@ $\mathrm{Zn}$. The anti-corrosion property would enhance the electrochemical performance of BTO@Zn. To further evaluate the behavior of $\mathrm{Zn}$ plating/stripping, galvanostatic cycling measurements are performed. As displayed in Fig. 2, a tip can be obviously observed in the voltage profiles of the initial charge process in the symmetric cell based on bare $\mathrm{Zn}$ (Zn-symmetric cell), which could be ascribed to the spatial variation of $\mathrm{Zn}$ dendrites along the bare $\mathrm{Zn}$ anode surface [45]. In contrast, the voltage profiles of the initial charge process in the symmetric cell based on BTO@Zn (BTO@Znsymmetric cell) are smoother, whose polarization is lower than that of the $\mathrm{Zn}$-symmetric cell. The ordered zinc ion migration can be obtained under the electric field, which is furnished by the directional dipoles of BTO layer. Therefore, the $\mathrm{Zn}$ dendrite growth is suppressed and the kinetics of zinc ion migration is enhanced. Subsequently, after cycling at $1 \mathrm{~mA} \mathrm{~cm}{ }^{-2}$ with capacity of $1 \mathrm{mAh} \mathrm{cm}{ }^{-2}$, the BTO@Znsymmetric cell exhibits an improved cycling stability over $2000 \mathrm{~h}$ in Fig. 2a. Negligible difference of the 250th, 500th and 1000th cycles displays remarkable cycling stability. When the current density and areal capacity are increased to $5 \mathrm{~mA} \mathrm{~cm}{ }^{-2}$ and $2.5 \mathrm{mAh} \mathrm{cm}^{-2}$, respectively, the BTO@ $\mathrm{Zn}$-symmetric cell operates for over $1500 \mathrm{~h}$ (Fig. 2b). The voltage profiles of the 500th and 1000th cycles are nearly in accordance. The rate performance of BTO@Zn-symmetric cell foil is illustrated in Fig. S5. At $8 \mathrm{~mA} \mathrm{~cm}^{-2}$ with capacity of $8 \mathrm{mAh} \mathrm{cm}^{-2}$, the voltage profiles of BTO@Zn-symmetric cell keep stable while the one employing bare $\mathrm{Zn}$ foil fails. In order to explore the positive properties of the BTO interphase for the symmetric cell, the electrochemical impedance technique was employed. Compared with the $\mathrm{Zn}$-symmetric cell, it can be found that the reduced charge transfer resistance is observed for BTO@Zn-symmetric cell (Fig. S6), which can be attributed to the even zinc ion migration on the artificial interphase. The even zinc ion migration can be achieved under the electric filed, which is provided by the aligned dipoles of BTO. Therefore, the reversible $\mathrm{Zn}$ plating/ stripping is enhanced and $\mathrm{Zn}$ dendrites are alleviated. It is reasonably concluded that the BTO layer enables $\mathrm{Zn}$ anode to achieve long-term cycle stability and high rate performance. In Fig. S7a, the polarization voltage of BTO@Zn is $84 \mathrm{mV}$ in the BTO@Zn-Ti cell, which is smaller than that of bare $\mathrm{Zn}$ foil $(115 \mathrm{mV})$ in the $\mathrm{Zn}-\mathrm{Ti}$ cell. The Coulombic efficiency (CE) of bare $\mathrm{Zn}$ foil is $89 \%$, which is lower than 

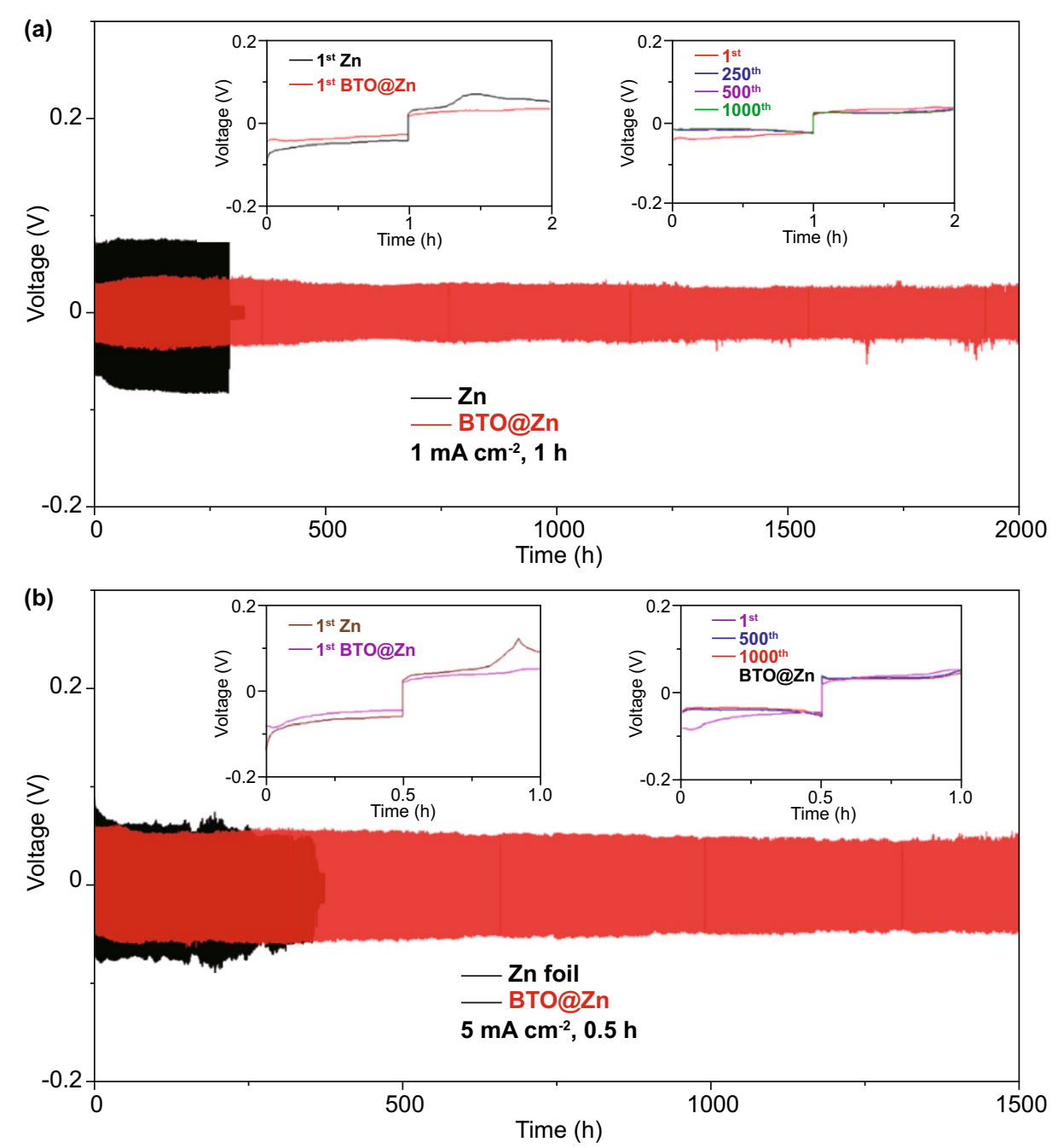

Fig. 2 Cycling performance of the symmetric cells with Zn and BTO@Zn, respectively: a at $1 \mathrm{~mA} \mathrm{~cm}^{-2}$ with capacity of $1 \mathrm{mAh} \mathrm{cm}^{-2}$ and $\mathbf{b}$ at $5 \mathrm{~mA} \mathrm{~cm}{ }^{-2}$ with capacity of $2.5 \mathrm{mAh} \mathrm{cm}^{-2}$. The insets reveal the detailed corresponding voltage profiles at various current densities and different cycles

that of BTO@Zn (97.8\%) for the first cycle in Fig. S7b. The higher Coulombic efficiency is obtained in the BTO@ $\mathrm{Zn}-\mathrm{Ti}$ cell due to the reduced side reactions caused by the $\mathrm{SO}_{4}{ }^{2-}$ anions. A certain amount of $\mathrm{SO}_{4}{ }^{2-}$ anions could be repelled by the BTO layer, which restricts the interaction between cations and anions. Accordingly, the side reactions would be restrained. Moreover, the desolvation process of hydrated zinc ion possibly benefits from the attraction of the $\mathrm{O}$ with enriched negative charge. Hydrogen bond perhaps forms to promote the $\mathrm{H}_{2} \mathrm{O}$ removal from hydrated $\mathrm{Zn}^{2+}$. Therefore, $\mathrm{Zn}$ plating needs less energy. It is noteworthy that the nucleation stage is vital for understanding behaviors of $\mathrm{Zn}$ dendrites [46]. There is a voltage dip at the beginning of the $\mathrm{Zn}$ plating, which indicates $\mathrm{Zn}$ nucleates on the surface of electrodes. The voltage dip for BTO@Zn is smaller than that of bare Zn. The nucleation overpotential of BTO@ $\mathrm{Zn}$ is $39 \mathrm{mV}$ in comparison with $49 \mathrm{mV}$ of $\mathrm{Zn}$, clarifying that BTO layer could facilitate $\mathrm{Zn}$ ion transport due to the dipoles. Additionally, at this impetuous current condition, the $\mathrm{Zn}-\mathrm{Ti}$ cell holds for only 8 cycles (16 h), but the BTO@ $\mathrm{Zn}-\mathrm{Ti}$ cell can operate for 14 cycles ( $28 \mathrm{~h}$ ) (Fig. S7b). It is indicated that the reversibility of $\mathrm{Zn}$ plating/stripping could be enhanced by the BTO SEI.

To further understand the process of Zn plating/stripping, the morphologies of various $\mathrm{Zn}$ electrodes are displayed by SEM images in Fig. 3. Figure 3a presents the surface of 
(a)

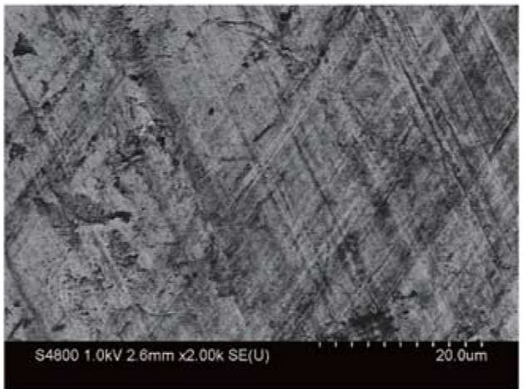

(b)

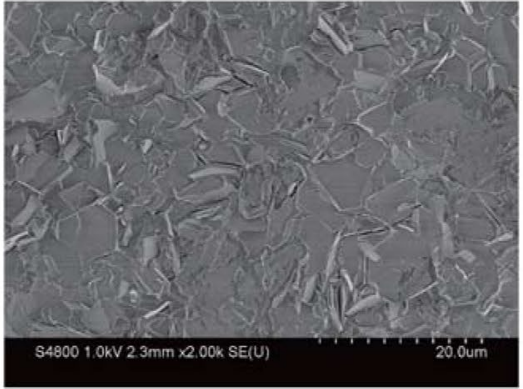

(c)

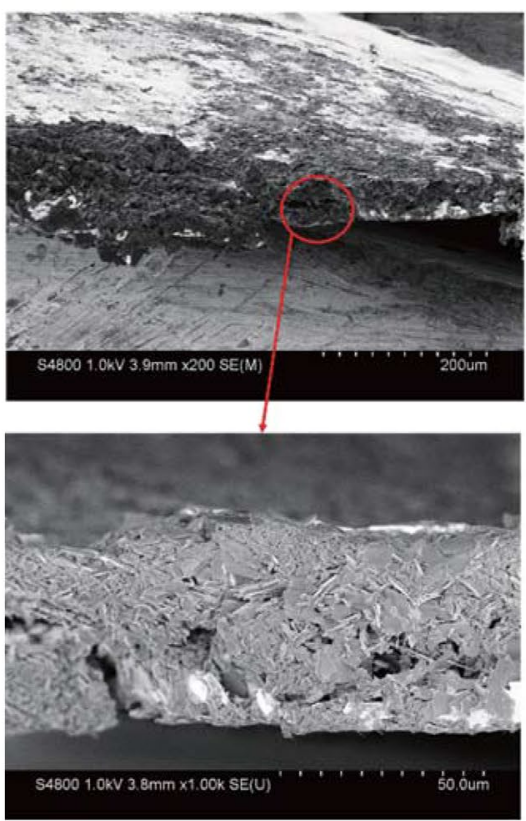

(d)

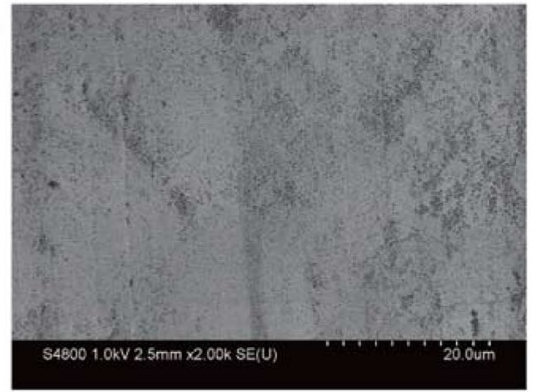

(e)

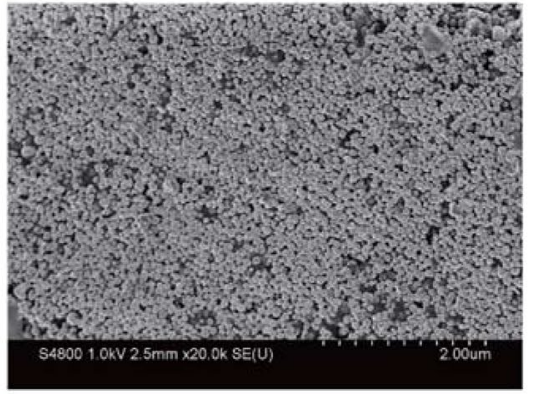

(f)
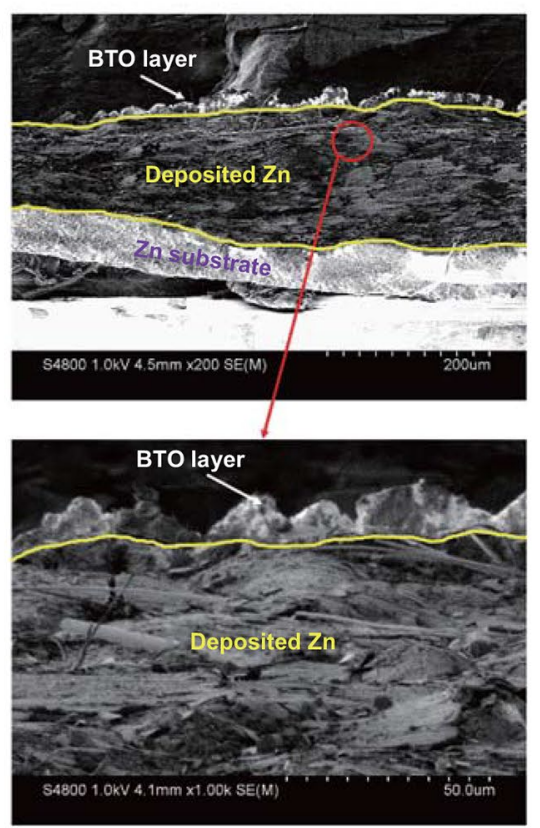

Fig. 3 SEM images of the anode morphology: a-c bare Zn and d-f BTO@Zn foils. a, $\mathbf{d}$ before and $\mathbf{b}, \mathbf{c}$ and $\mathbf{e}, \mathbf{f}$ after $100 \mathrm{cycles}$ at $1 \mathrm{~mA} \mathrm{~cm}^{-2}$ and $1 \mathrm{mAh} \mathrm{cm} \mathrm{cm}^{-2}$ of the symmetric cells. Highlight typical cross section SEM images in $\mathbf{c}$ and $\mathbf{f}$. BTO layer, deposited $\mathrm{Zn}$ and $\mathrm{Zn}$ foils are separated by the yellow lines. (Color figure online)

bare $\mathrm{Zn}$ foil, before cycling. After 100 cycles at $1 \mathrm{~mA} \mathrm{~cm}{ }^{-2}$ with capacity of $1 \mathrm{mAh} \mathrm{cm}{ }^{-2}, \mathrm{Zn}$ is plated unevenly on bare $\mathrm{Zn}$ foil, which can be obviously observed in Fig. $3 \mathrm{~b}$. It is noteworthy that $\mathrm{Zn}$ is liable to be plated at the initial nucleation area, and then, protrusions grow up. Moreover, bare $\mathrm{Zn}$ is severely pulverized and the morphology changes impressively (Fig. 3c). By contrast, the morphology of BTO@Zn could remain smooth and flat after cycling (Fig. 3d before and Fig. 3e after cycling). Compared to the case in Fig. 3c, a dense uniform Zn layer is plated between BTO layer and $\mathrm{Zn}$ foil in the enlarged SEM image of Fig. 3f. As it is well known, the by-product $\mathrm{Zn}_{4} \mathrm{SO}_{4}(\mathrm{OH})_{6} \cdot 5 \mathrm{H}_{2} \mathrm{O}$ 
would be produced on the bare $\mathrm{Zn}$ anode during cycling, which could affect the $\mathrm{Zn}$ deposition negatively. Although it can be found that the by-product is produced on BTO layer as well (Fig. S8), the side reaction could be reduced to a certain degree, which is consistent with the higher Coulombic efficiency of BTO@Zn-Ti cells. Under the same experimental conditions, the BTO-protected Zn delivers higher reversible $\mathrm{Zn}$ plating/stripping processes. Moreover, it also shows a typical diffraction peak at $31.5^{\circ}$ in Fig. S8, which demonstrates the high stability of BTO after long cycling.

\subsection{Electrochemical Performance of the $\mathrm{Zn}-\mathrm{MnO}_{2}$ Batteries}

To clarify the feasibility of this potential strategy for practical application, $\mathrm{Zn}-\mathrm{MnO}_{2}$ batteries using bare $\mathrm{Zn}$ and BTO@Zn (BTO@Zn- $\mathrm{MnO}_{2}$ batteries) are fabricated and tested. XRD pattern of the material cathode reveals monoclinic structure (Fig. S9). The SEM image exhibits flake-like morphology of $\mathrm{MnO}_{2}$ in Fig. S10. 0.1 $\mathrm{M} \mathrm{MnSO}_{4}$ served as additive to alleviate the dissolution of $\mathrm{Mn}^{2+}$ derived from the reduction of $\mathrm{Mn}^{4+}$ [47]. The cyclic voltammograms (CV) of both batteries are presented in Fig. 4a. The cathodic peaks of BTO@ $\mathrm{Zn}-\mathrm{MnO}_{2}$ battery at 1.22/1.36 V are higher than the ones $(1.19 / 1.35 \mathrm{~V})$ of $\mathrm{Zn}-\mathrm{MnO}_{2}$ battery based on bare $\mathrm{Zn}$, indicating the higher kinetics of zinc ion insertion in BTO@ $\mathrm{Zn}-\mathrm{MnO}_{2}$ battery. Additionally, to further demonstrate the fast kinetics of zinc ion insertion in BTO@ $\mathrm{Zn}-\mathrm{MnO}_{2}$ batteries, the discharge galvanostatic intermittent titration technique (GITT) is carried out. As presented in Fig. S11, a higher discharge plateau is observed in the BTO@ $\mathrm{Zn}-\mathrm{MnO}_{2}$ battery, which indicates the faster kinetics of zinc ion insertion. The favorable kinetics of zinc ion insertion in BTO@ $\mathrm{Zn}-\mathrm{MnO}_{2}$ battery can be ascribed to uniform ion pathways and the regulated zinc ion migration on the BTO@Zn surface. Similarly, benefitting from the BTO layer, the fast kinetics of $\mathrm{Zn}$ plating can be achieved during the charging process. The surface electric field of BTO is switchable along with the applied electric field. Uniform $\mathrm{Zn}$ plating can be achieved under the even electric field at the anode/ electrolyte interface. It can be found that the anodic peak for BTO@Zn foil at $1.57 \mathrm{~V}$ is smaller than the one $(1.59 \mathrm{~V})$ for bare $\mathrm{Zn}$, which could be ascribed to the kinetics of $\mathrm{Zn}$ plating caused by the uniform zinc ion migration. Coincident conclusion can be obtained in galvanostatic charge/discharge (GCD) curves for the two batteries. In Fig. 4b, two discharge plateaus are observed in the $\mathrm{Zn}-\mathrm{MnO}_{2}$ batteries. During discharging process, the manganese oxidation state is changed from $\mathrm{Mn}(\mathrm{IV})$ to $\mathrm{Mn}(\mathrm{III}) / \mathrm{Mn}(\mathrm{II})$, which are corresponding to
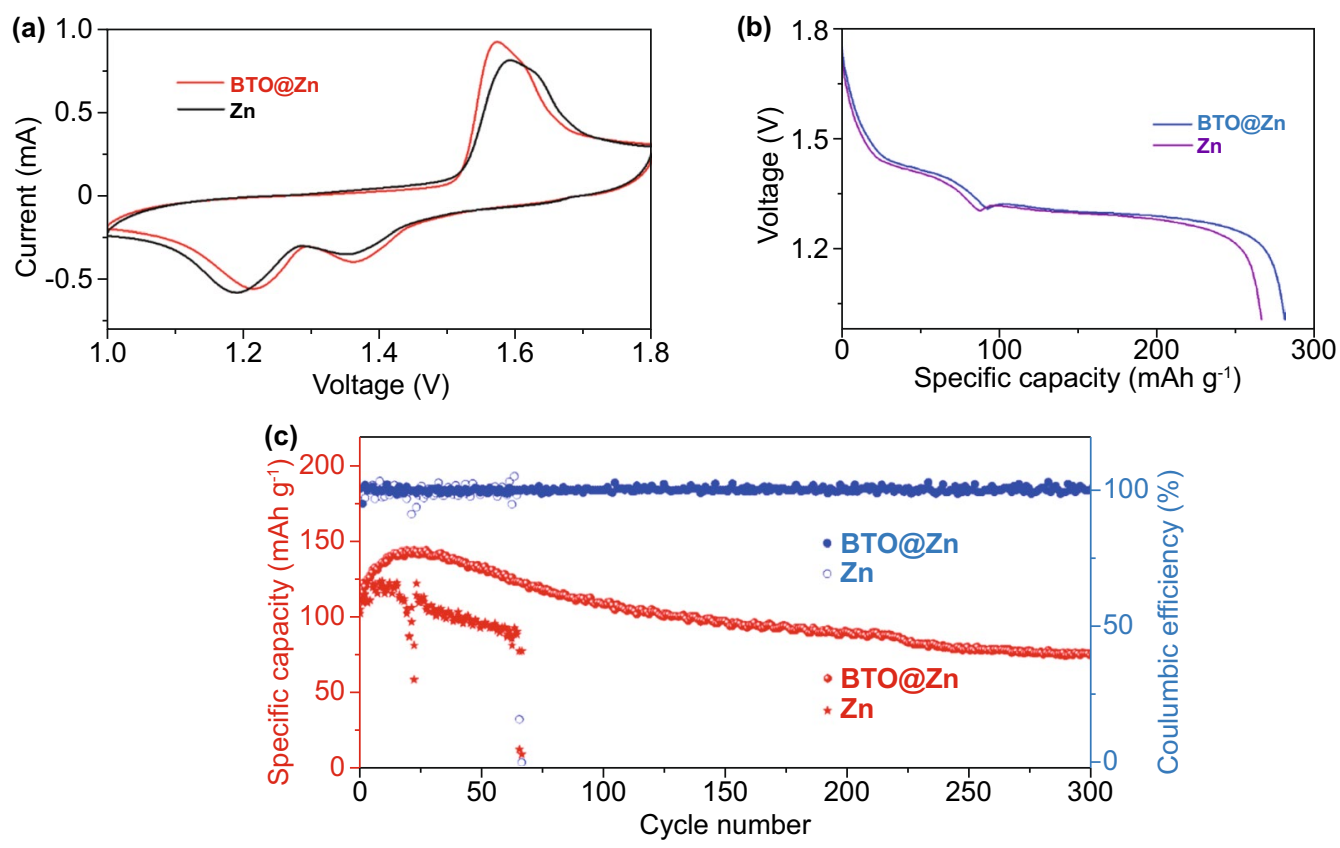

Fig. 4 Electrochemical performance of $\mathrm{Zn}-\mathrm{MnO}_{2}$ batteries based on bare $\mathrm{Zn}$ and BTO@ $\mathrm{Zn}$ foil, respectively. a CV profiles of the 2nd cycle at $1 \mathrm{mV} \mathrm{s}^{-1}$. b GCD curves of the 2nd discharge process at $200 \mathrm{~mA} \mathrm{~g}^{-1}$. c Cycling performance at $2 \mathrm{~A} \mathrm{~g}^{-1}$ 
the formation of $\mathrm{Zn}_{x} \mathrm{MnO}_{2}$ and $\mathrm{ZnMn}_{2} \mathrm{O}_{4}$ [48]. The BTO@ $\mathrm{Zn}-\mathrm{MnO}_{2}$ battery shows a higher discharge plateau compared to the $\mathrm{Zn}-\mathrm{MnO}_{2}$ battery, which is corresponded to the $\mathrm{CV}$ profiles. The rate capabilities of $\mathrm{Zn}-\mathrm{MnO}_{2}$ batteries based on Zn and BTO@Zn are shown in Fig. S12. It can be found that the BTO@ $\mathrm{Zn}-\mathrm{MnO}_{2}$ battery shows higher rate capability, which further demonstrates the faster kinetics of Zn ion migration on BTO@ $\mathrm{Zn}$ due to the BTO layer. Impressively, at $2 \mathrm{~A} \mathrm{~g}^{-1}$, the battery with BTO@Zn anode displays a capacity retention of $67 \%$ after 300 cycles; however, the battery with $\mathrm{Zn}$ anode reveals only $16 \%$ capacity retention at the 66th cycle and fails at the next cycle (Fig. 4c). It manifests BTO@Zn can undergo fierce stripping/plating to ensure nearly $100 \%$ Coulombic efficiency after 300 cycles at $2 \mathrm{~A} \mathrm{~g}^{-1}$.

\section{Conclusion}

$\mathrm{Zn}$ dendrite growth is one of the serious problems affecting the stability of $Z n$ anode. Engineering an artificial SEI on the surface of $\mathrm{Zn}$ is an effective strategy to restrain $\mathrm{Zn}$ dendrite growth. In this work, it is demonstrated that the artificial SEI based on BTO could effectively suppress $\mathrm{Zn}$ dendrites. The BTO layer provides numerous aligned dipoles whose electric polarization can be switched with the applied electric field. During cycling process, even electric field on the surface of BTO layer can induce the ordered zinc ion migration. Compared to bare Zn, BTO@Zn anode possesses remarkable cycling stability and rate performance. The BTO@Zn-symmetric cell presents a decent cycling stability over $2000 \mathrm{~h}$ (1000 cycles) at $1 \mathrm{~mA} \mathrm{~cm}{ }^{-2}$ with capacity of $1 \mathrm{mAh} \mathrm{cm}^{-2}$. What is more, when the current density and areal capacity is $5 \mathrm{~mA} \mathrm{~cm}^{-2}$ and $2.5 \mathrm{mAh} \mathrm{cm}^{-2}$, respectively, the BTO@Znsymmetric cell can operate over 1500 cycles. Demonstrated in aqueous $\mathrm{Zn}-\mathrm{MnO}_{2}$ batteries, the $\mathrm{BTO} @ \mathrm{Zn}-\mathrm{MnO}_{2}$ battery reveals a higher rate capability and nearly $100 \%$ Coulombic efficiency after 300 cycles at $2 \mathrm{~A} \mathrm{~g}^{-1}$. This study is expected to enlighten the further research in $\mathrm{Zn}$ anode.

Acknowledgements The authors are grateful for the partial financial support from the National Natural Science Foundation of China (21935003 and 21805182), National Key Research and Development Plan (2016YFB0901503), Shanghai Pujiang Program (18PJ1403800). The authors thank the support from the Hundreds of Talents program of Sun Yat-sen University. Computational resources are provided by the National Supercomputing Center in Shenzhen.

Open Access This article is licensed under a Creative Commons Attribution 4.0 International License, which permits use, sharing, adaptation, distribution and reproduction in any medium or format, as long as you give appropriate credit to the original author(s) and the source, provide a link to the Creative Commons licence, and indicate if changes were made. The images or other third party material in this article are included in the article's Creative Commons licence, unless indicated otherwise in a credit line to the material. If material is not included in the article's Creative Commons licence and your intended use is not permitted by statutory regulation or exceeds the permitted use, you will need to obtain permission directly from the copyright holder. To view a copy of this licence, visit http://creativecommons.org/licenses/by/4.0/.

Supplementary Information The online version of this article (https://doi.org/10.1007/s40820-021-00599-2).

\section{References}

1. G. Fang, J. Zhou, A. Pan, S. Liang, Recent advances in aqueous zinc-ion batteries. ACS Energy Lett. 3, 2480-2501 (2018). https://doi.org/10.1021/acsenergylett.8b01426

2. J. Yi, P. Liang, X. Liu, K. Wu, Y. Liu et al., Challenges, mitigation strategies and perspectives in development of zincelectrode materials and fabrication for rechargeable zinc-air batteries. Energy Environ. Sci. 11, 3075-3095 (2018). https ://doi.org/10.1039/c8ee01991f

3. P. Liang, J. Yi, X. Liu, K. Wu, Z. Wang et al., Highly reversible zn anode enabled by controllable formation of nucleation sites for Zn-based batteries. Adv. Funct. Mater. 30, 1908528 (2020). https://doi.org/10.1002/adfm.201908528

4. J. Cao, D. Zhang, X. Zhang, M. Sawangphruk, J. Qin et al., A universal and facile approach to suppress dendrite formation for a $\mathrm{Zn}$ and Li metal anode. J. Mater. Chem. A 8, 9331-9344 (2020). https://doi.org/10.1039/d0ta02486d

5. X. Liu, J. Yi, K. Wu, Y. Jiang, Y. Liu et al., Rechargeable $\mathrm{Zn}-\mathrm{MnO}_{2}$ batteries: advances, challenges and perspectives. Nanotechnology 31, 122001 (2020). https://doi. org/10.1088/1361-6528/ab5b38

6. C. Deng, X. Xie, J. Han, Y. Tang, J. Gao et al., A sievefunctional and uniform-porous kaolin layer toward stable zinc metal anode. Adv. Funct. Mater. 30, 2000599 (2020). https://doi.org/10.1002/adfm.202000599

7. J. Cao, D. Zhang, X. Zhang, S. Wang, J. Han et al., Mechanochemical reactions of $\mathrm{MnO}_{2}$ and graphite nanosheets as a durable zinc ion battery cathode. Appl. Surf. Sci. 534, 147630 (2020). https://doi.org/10.1016/j.apsusc.2020.14763 0

8. P. Hu, T. Zhu, X. Wang, X. Wei, M. Yan et al., Highly durable $\mathrm{Na}_{2} \mathrm{~V}_{6} \mathrm{O}_{16} \cdot 1.63 \mathrm{H}_{2} \mathrm{O}$ nanowire cathode for aqueous 
zinc-ion battery. Nano Lett. 18, 1758-1763 (2018). https:// doi.org/10.1021/acs.nanolett.7b04889

9. N. Zhang, Y. Dong, M. Jia, X. Bian, Y. Wang et al., Rechargeable aqueous $\mathrm{Zn}-\mathrm{V}_{2} \mathrm{O}_{5}$ battery with high energy density and long cycle life. ACS Energy Lett. 3, 1366-1372 (2018). https ://doi.org/10.1021/acsenergylett.8b00565

10. H. Li, L. Ma, C. Han, Z. Wang, Z. Liu et al., Advanced rechargeable zinc-based batteries: recent progress and future perspectives. Nano Energy 62, 550-587 (2019). https://doi. org/10.1016/j.nanoen.2019.05.059

11. R. Venkatkarthick, N. Rodthongkum, X. Zhang, S. Wang, P. Pattananuwat et al., Vanadium-based oxide on two-dimensional vanadium carbide mxene $\left(\mathrm{V}_{2} \mathrm{O}_{x} @ \mathrm{~V}_{2} \mathrm{CT}_{x}\right)$ as cathode for rechargeable aqueous zinc-ion batteries. ACS Appl. Energy Mater. 3, 4677-4689 (2020). https://doi.org/10.1021/acsae m.0c00309

12. L. Zhang, L. Chen, X. Zhou, Z. Liu, Towards high-voltage aqueous metal-ion batteries beyond $1.5 \mathrm{~V}$ : the zinc/zinc hexacyanoferrate system. Adv. Energy Mater. 5, 1400930 (2015). https://doi.org/10.1002/aenm.201400930

13. M. Song, H. Tan, D. Chao, H.J. Fan, Recent advances in Znion batteries. Adv. Funct. Mater. 28, 1802564 (2018). https:// doi.org/10.1002/adfm.201802564

14. K. Wu, J. Huang, J. Yi, X. Liu, Y. Liu et al., Recent advances in polymer electrolytes for zinc ion batteries: mechanisms, properties, and perspectives. Adv. Energy Mater. 10, 1903977 (2020). https://doi.org/10.1002/aenm.201903977

15. H. Yu, Y.G. So, Y. Ren, T. Wu, G. Guo et al., Temperaturesensitive structure evolution of lithium-manganese-rich layered oxides for lithium-ion batteries. J. Am. Chem. Soc. 140, 15279-15289 (2018). https://doi.org/10.1021/jacs.8b07858

16. X. Zhang, H. Yu, Crystalline domain battery materials. Acc. Chem. Res. 53, 368-379 (2020). https://doi.org/10.1021/acs. accounts.9b00457

17. J. Abdulla, J. Cao, P. Wangyao, J. Qin, Review on the suppression of $\mathrm{Zn}$ dendrite for high performance of $\mathrm{Zn}$ ion battery. J. Met. Mater. Miner. 30, 1-8 (2020). https://doi. org/10.14456/jmmm.2020.31

18. L. Kang, M. Cui, F. Jiang, Y. Gao, H. Luo et al., Nanoporous $\mathrm{CaCO}_{3}$ coatings enabled uniform $\mathrm{Zn}$ stripping/plating for long-life zinc rechargeable aqueous batteries. Adv. Energy Mater. 8, 1801090 (2018). https://doi.org/10.1002/ aenm.201801090

19. Z. Zhao, J. Zhao, Z. Hu, J. Li, J. Li et al., Long-life and deeply rechargeable aqueous $\mathrm{Zn}$ anodes enabled by a multifunctional brightener-inspired interphase. Energy Environ. Sci. 12, 1938-1949 (2019). https://doi.org/10.1039/c9ee0 $0596 \mathrm{j}$

20. R. Zhao, Y. Yang, G. Liu, R. Zhu, J. Huang et al., Redirected $\mathrm{Zn}$ electrodeposition by an anti-corrosion elastic constraint for highly reversible $\mathrm{Zn}$ anodes. Adv. Funct. Mater. (2020). https ://doi.org/10.1002/adfm.202001867

21. K. Lolupiman, P. Wangyao, J. Qin, Electrodeposition of Zn/ $\mathrm{TiO}_{2}$ composite coatings for anode materials of zinc ion battery. J. Met. Mater. Miner. 29, 120-126 (2019). https://doi. org/10.14456/jmmm.2019.55
22. H. Yang, Z. Chang, Y. Qiao, H. Deng, X. Mu et al., Constructing a super-saturated electrolyte front surface for stable rechargeable aqueous zinc batteries. Angew. Chem. Int. Ed. 59, 9377-9381 (2020). https://doi.org/10.1002/anie.20200 1844

23. M. Liu, L. Yang, H. Liu, A. Amine, Q. Zhao et al., Artificial solid-electrolyte interface facilitating dendrite-free zinc metal anodes via nanowetting effect. ACS Appl. Mater. Interfaces 11, 32046-32051 (2019). https://doi.org/10.1021/acsam i. 9 b1 1243

24. X. Xie, S. Liang, J. Gao, S. Guo, J. Guo et al., Manipulating the ion-transfer kinetics and interface stability for high-performance zinc metal anodes. Energy Environ. Sci. 13, 503-510 (2020). https://doi.org/10.1039/c9ee03545a

25. Q. Yang, Y. Guo, B. Yan, C. Wang, Z. Liu et al., Hydrogensubstituted graphdiyne ion tunnels directing concentration redistribution for commercial-grade dendrite-free zinc anodes. Adv. Mater. 32, 2001755 (2020). https://doi.org/10.1002/ adma.202001755

26. Z. Peng, S.A. Freunberger, Y. Chen, P.G. Bruce, A reversible and higher-rate $\mathrm{Li}-\mathrm{O}_{2}$ battery. Science 337, 563 (2012). https ://doi.org/10.1126/science.1223985

27. H. Palneedi, M. Peddigari, G.T. Hwang, D.Y. Jeong, J. Ryu, High-performance dielectric ceramic films for energy storage capacitors: progress and outlook. Adv. Funct. Mater. 28, 1803665 (2018). https://doi.org/10.1002/adfm.201803665

28. K. Bi, M. Bi, Y. Hao, W. Luo, Z. Cai et al., Ultrafine core-shell $\mathrm{BaTiO}_{3} @ \mathrm{SiO}_{2}$ structures for nanocomposite capacitors with high energy density. Nano Energy 51, 513-523 (2018). https ://doi.org/10.1016/j.nanoen.2018.07.006

29. M.H. Braga, J.E. Oliveira, T. Kai, A.J. Murchison, A.J. Bard et al., Extraordinary dielectric properties at heterojunctions of amorphous ferroelectrics. J. Am. Chem. Soc. 140, 1796817976 (2018). https://doi.org/10.1021/jacs.8b09603

30. L.B. Kong, T.S. Zhang, J. Ma, F. Boey, Progress in synthesis of ferroelectric ceramic materials via high-energy mechanochemical technique. Prog. Mater. Sci. 53, 207-322 (2008). https://doi.org/10.1016/j.pmatsci.2007.05.001

31. T. Yim, S.H. Han, N.H. Park, M.S. Park, J.H. Lee et al., Effective polysulfide rejection by dipole-aligned $\mathrm{BaTiO}_{3}$ coated separator in lithium-sulfur batteries. Adv. Funct. Mater. 26, 7817-7823 (2016). https://doi.org/10.1002/adfm.201602498

32. C.H. Ahn, K.M. Rabe, J.M. Triscone, Ferroelectricity at the nanoscale: local polarization in oxide thin films and heterostructures. Science 303, 488-491 (2004). https://doi. org/10.1126/science.1092508

33. W. Ma, L.E. Cross, Flexoelectricity of barium titanate. Appl. Phys. Lett. 88, 232902 (2006). https://doi.org/10.1063/1.22113 09

34. P.E. Blochl, Projector augmented-wave method. Phys. Rev. B 50, 17953-17979 (1994). https://doi.org/10.1103/PhysR evB.50.17953

35. G. Kresse, J. Furthmüjller, Efficient iterative schemes for ab initio total-energy calculations using a plane-wave basis set. Phys. Rev. B 54, 11169-11186 (1996). https://doi.org/10.1103/ PhysRevB.54.11169 
36. G. Kresse, J. Furthmüjller, Efficiency of ab-initio total energy calculations for metals and semiconductors using a plane-wave basis set. Comput. Mater. Sci. 6, 15-50 (1996). https://doi. org/10.1016/0927-0256(96)00008-0

37. J.P. Perdew, K. Burke, M. Ernzerhof, Generalized gradient approximation made simple. Phys. Rev. Lett. 77, 3865-3868 (1996). https://doi.org/10.1103/PhysRevLett.77.3865

38. J.M. Yun, J.H. Shin, J. Ryu, N.M. Shinde, K.H. Kim, Piezoelectric performance of cubic-phase $\mathrm{BaTiO}_{3}$ nanoparticles vertically aligned via electric field. Adv. Sustain. Syst. 2, 1700133 (2018). https://doi.org/10.1002/adsu.201700133

39. D. Chao, W. Zhou, F. Xie, C. Ye, H. Li et al., Roadmap for advanced aqueous batteries: from design of materials to applications. Sci. Adv. 6, eaba4098 (2020). https://doi.org/10.1126/ sciadv.aba4098

40. Z. Hou, H. Tan, Y. Gao, M. Li, Z. Lu et al., Tailoring desolvation kinetics enables stable zinc metal anodes. J. Mater. Chem. A 8, 19367-19374 (2020). https://doi.org/10.1039/d0ta06622b

41. Y. Cui, Q. Zhao, X. Wu, Z. Wang, R. Qin et al., Quasi-solid single $\mathrm{Zn}$-ion conductor with high conductivity enabling dendrite-free Zn metal anode. Energy Storage Mater. 27, 1-8 (2020). https://doi.org/10.1016/j.ensm.2020.01.003

42. Y. Cui, Q. Zhao, X. Wu, X. Chen, J. Yang et al., An interface-bridged organic-inorganic layer that suppresses dendrite formation and side reactions for ultra-long-life aqueous zinc metal anodes. Angew. Chem. Int. Ed. 59, 16594-16601 (2020). https://doi.org/10.1002/anie.202005472
43. J. Zheng, Y. Hou, Y. Duan, X. Song, Y. Wei et al., Janus solidliquid interface enabling ultrahigh charging and discharging rate for advanced lithium-ion batteries. Nano Lett. 15, 61026109 (2015). https://doi.org/10.1021/acs.nanolett.5b02379

44. Q. Zhang, J. Luan, Y. Tang, X. Ji, H.Y. Wang, Interfacial design of dendrite-free zinc anodes for aqueous zinc-ion batteries. Angew. Chem. Int. Ed. 59, 13180-13191 (2020). https ://doi.org/10.1002/anie.202000162

45. K.-H. Chen, K.N. Wood, E. Kazyak, W.S. LePage, A.L. Davis et al., Dead lithium: mass transport effects on voltage, capacity, and failure of lithium metal anodes. J. Mater. Chem. A 5, 11671-11681 (2017). https://doi.org/10.1039/c7ta00371d

46. Y. Zeng, X. Zhang, R. Qin, X. Liu, P. Fang et al., Dendrite-free zinc deposition induced by multifunctional cnt frameworks for stable flexible Zn-ion batteries. Adv. Mater. 31, e1903675 (2019). https://doi.org/10.1002/adma.201903675

47. H. Pan, Y. Shao, P. Yan, Y. Cheng, K.S. Han et al., Reversible aqueous zinc/manganese oxide energy storage from conversion reactions. Nat. Energy 1, 16039 (2016). https://doi. org/10.1038/nenergy.2016.39

48. Z.M.H. Alfaruqi, S. Islam, D.Y. Putro, V. Mathew, S. Kim et al., Structural transformation and electrochemical study of layered $\mathrm{MnO}_{2}$ in rechargeable aqueous zinc-ion battery. Electrochim. Acta 276, 1-11 (2018). https://doi.org/10.1016/j.elect acta.2018.04.139 